\title{
The Economy of Sustainability: Some Consequences on the Economic Theory
}

\author{
Giovanni Antonio Cossiga \\ Università Sapienza, Rome, Italy \\ Email: g.cossiga@gmail.com
}

How to cite this paper: Cossiga, G.A. (2019) The Economy of Sustainability: Some Consequences on the Economic Theory. Theoretical Economics Letters, 9, 3034-3064. https://doi.org/10.4236/tel.2019.98187

Received: August 28, 2019

Accepted: December 27, 2019

Published: December 30, 2019

Copyright ( 2019 by author(s) and Scientific Research Publishing Inc. This work is licensed under the Creative Commons Attribution International License (CC BY 4.0).

http://creativecommons.org/licenses/by/4.0/ (c) (i) Open Access

\begin{abstract}
The economy of sustainability is usually portraying the tendency to stability as a universal law regulating the development of the mankind and nature relationship. The trend towards the stability of economic systems is the guarantor of a constant and regular growth, in accordance with the evolution of the environment around us. It follows that the deviation from the stability rule is certainly possible but with some penalties. The main penalty is the transformation of the linear and constant growth into the conjuncture sinuous movement, so that the corrective recession would be introduced into the economic circuit. Recession intended as a tool to bring the deviated system back to the natural condition of stability. According to this point of view, the recession is a sin to be paid in the economy management and there would be no way to avoid to pay this price. Therefore, attempts to avoid the penalties imposed to correct the system may be reckless. Trying to avoid the penalty means only to refuse now that damage which would allow the following return to the serenity of natural stability. It follows that the inexhaustible attempts to correct the economic trend in favor of a constant growth line do not take into due consideration that only the stable condition of the economy can guarantee that tomorrow wouldn't be worse than today. Therefore, attempting to straighten the sinuous line of the cycle is absurd, at least if we continue to remain inside the instability sub-world. The result is that the ultra-Keynesian policies to support the cycle correspond to an irrepressible desire to take action in order to mitigate the damage. But the recession is a cure that sooner or later must be adopted. So, the options offered by the fiscal and monetary policies to support the cycle can have some effect, even satisfactory, but only in the short term. That is, they offer the possibility to drag over time the showdown with the immanent tendency towards stability. But sooner or later the tendency towards recession will return even more urgent and it would be therefore appropriate to accept a present damage for an advantage
\end{abstract}


(constant growth) in the future, within an economic scenario once again stable.

\section{Keywords}

Sustainability, Economic Theory, Deflation, Inflation, Fiscal and Monetary Policies

\section{Introduction}

In a context of sustainable economy, the scenario of the stable economy always follows a constant trend, slightly rising depending on the potentials of the system. In a stable system, therefore, the expectation of a tomorrow like today-in terms of expectations in the economic field-is quite reasonable. This approach shouldn't be surprising. It's enough to say that the communities carry in their collective DNA this expectation of a tomorrow that wouldn't be different from today, regarding the economic perspectives. Not otherwise, we can explain the disillusionment taking individuals and communities when the economy turns more or less rapidly towards recession and cyclical involution. In this regard, we can argue that the expectation of a linear growth represents a collective aspiration in harmony with the stability universe. Of which, therefore, it's a sort of "echo" able to receive information, even informal, on the path followed by the economy.

In fact, it is reasonable to think that the long permanence of humanity on the planet is somehow assisted by a fundamental law concerning the economy's path. A law that over time must safeguard the compatible use of natural resources, for the benefit of future generations who should be able to count on them for their own survival. It follows that sustainability can be defined as the rule to preserve natural resources over time. A mission that is certainly not subject to the rules of selfishness but must find a substantial support in a fundamental law, not so different from those governing the world of physics. In short, the rule of stability and sustainability understood as possible growth inside a context of natural resources conservation.

According to this approach, the norm for good economy management cannot allow deviations from the stability of economic systems. And if this deviation actually occurs, the rule of stability must therefore involve models for the correction of systems that become unstable, which necessarily operate without any guidance but the natural law. Anyway, it's acting with an operational gradualism allowed by the times of nature. Therefore, even long times that may not be compatible with the time of a human generation.

Therefore, the natural rule oversees the stability of the economy course. Obviously, the relationship between humanity and nature doesn't qualify as a stable equilibrium. The balanced situation is instead the result of corrections on the in- 
stability path, which unfortunately is actually the norm in the current economic landscape. It's like saying that the even marked deviations from the stability path are characterized by pauses in the natural development mechanism. To hang up the balance of economic systems or at least to reduce the excessive waste of natural resources, the economy suffers a pause or a regression in terms of development, in this way, is thus attenuated the gap between the sustainability pathway and the potential degradation resulting from the excesses and from forcing the economy development.

Therefore, the balance of economic systems is always in fieri, in the sense that any deviation from the natural path would impose slowdowns, blockages or regression of natural development, since the rule of balance between economy and nature cannot be forced. It follows that the economy in pause or recession is always the consequence of a natural corrective process, which appears in the sub-world of instability. It can be deduced that the most loyal behavior in the economy management should be always to have the positive expectation that the forces of natural correction will do their job.

In other words, the conjuncture cycle reversal and the recession are not to be considered evils in themselves but instead real treatments imposed by the corrective system, in the attempt to resolve the errors produced by the deviated development inside the economic structure. If this is a self-care, anyway a doubt remains about the consequences produced by measures to hinder or even just mitigate the strength of the economic crisis.

Perhaps the inactivity of those responsible for the economy management may also be inappropriate, because the social stability must be considered a relevant factor during the adverse phases of the economic conjuncture. Meaning that the balance between economy and nature should also include a balance in the distribution of resources within a community as well as in all countries and continents. So, within a community a wealth and income distribution in favor of a small circle of lucky people must be considered an aberration that the corrective system will try to correct over time. The times of the humanity-nature relationship may not be exactly compatible with the times of one or more generations. But we should consider them unequivocal and inevitable.

Equally we can think that a distribution of wealth and incomes among nations and continents just for the benefit of restricted privileged countries, as happened for the major European countries in the nineteenth century, is destined to change under the sign of a greater distribution equity. According to this point of view, the rise of the Asian continent and namely of China and India, in the following century should be interpreted in the sign of the distribution correction at a global level. Therefore, we can expect a similar phenomenon would concern Africa, which remained on the fringe of the redistribution process of global resources.

Just to say that the social and economic rebalancing of the most advanced countries, of Asia and later of Africa, is to be considered a phenomenon of natural correction in the redistribution of resources. A phenomenon that has led 
and will lead to a transfer of resources, consistent with the real essence of the natural law of balance between humanity and nature. Rebalancing occurs with historical times, but it is unequivocal and inevitable. Therefore, it makes no sense to oppose this natural process that is deeply rooted in the special relationship that ties all living beings to the nature around us.

\section{The Tendency to Stability of Economic Systems and How to Preserve It}

\subsection{If We Hinder the Natural Correction Process, There Could Be Consequences}

What to do in the event of a recession, or worse of a financial crisis? The answer seems quite difficult. At least under the point of view of the sustainability economy and, therefore, of the sub-world of instability for an economic system. The problem, of course, is the balance of the economy and therefore the return of altered systems to the correct sustainability ratio in the economy. First of all, because the growth of the economy is to be considered constant and without cyclical alternations when an economic system is maintained in the orbit of sustainability.

This is to say that a long period of constant and regular economic development can be assured if the economy management does not yield to the temptation to support growth, so forcing the relationship between economy and nature. Not only that, indeed, because it's highly probable that in a balanced condition would prevail the tendency to maximize the development potentials. Exactly the opposite of what happens in the sub-world of instability, where the economic situation is always trying to curb the potentials and to propose the recession, to let the overloaded system have a much needed pause.

It goes without saying that, when we are at the center of a sudden economic reversal, it's almost unavoidable to resort to neo-Keynesian maneuvers and to the accommodative monetary policy, in order to mitigate social damages. In fact, in the case of a strong reversal of the economic conjuncture, the greatest damage is felt by the weaker social categories, thus increasing the already too wide gap in the income range. Notwithstanding, falling into a ravine, even if it s Saturday, we should do everything to minimize damage. However, the fact remains that we could witness as a result of supportive measures-as it happens in fact-a mitigation of recessionary phenomena and a relatively quick return to a slow recovery. However, the interruption or décalage of the phenomenon will have some consequences, since the action was somehow opposing the correction natural mechanism.

It must be said that we can identify or at least estimate the quantum of the recession that could depend directly on the mechanism of natural correction and also the quantum of the conjunctural drop that instead could be due to errors-above all of a monetary nature-arising from the desire to give immediately some breath to the economy in crisis. The ' 29 great crisis was the final outcome of an incredible and irrational speculative wave that dragged the Stock 
Exchanges to a continuous upward. The reaction of the Central Banks and in particular of the FED was the control over the money quantity. ${ }^{1}$ In a sort of homage to a monetarist conception, the great nations at the time protagonists, then decided to hang up their currencies to gold, according to the ratio before the Great Crisis. ${ }^{2}$

These were decisions that essentially reduced the quantity of money available for the markets, actually exacerbating and emphasizing the underlying effect of the post-speculation crisis. It can be argued that the addition of monetary exasperation over the markets contributed a lot to the collapse of production and incomes in the 1930s. So much that the decision progressively adopted by the various states to abandon the Gold Standard was followed by a rapid improvement at the industrial and commercial level, while those who delayed to unhook the currency (Italy and France) suffered longer the serious repercussions of the economic crisis [1].

This brief glimpse is just to say that it's possible and seems even appropriate to distinguish between the natural correction and the correction for technical errors. The first one, if blocked, can produce medium-long term effects. Otherwise, we should not expect a negative legacy from solutions unblocking the effects produced by technical errors of the monetary and financial management. It must be said, moreover, that the management of the economy, according to sus${ }^{1}$ In 1933 Roosevelt removed independence of the Federal Reserve, then ordered to print money, left the gold standard, devalued the dollar. And here are the reactions of his advisors: "Feis made a gesture as if he wanted to give up everything. Douglas was completely in horror. Warburg declared clearly that this decree was demented and irresponsible. Douglas took leave with a Well, this is the end of western civilization". Instead, Keynes wrote to Roosevelt that he was the only hope of the liberal democracy: if he would fail, on the political scene only revolution and reaction would remain, fighting each other ... And he did not ask to give back the independence to the FED. John Maynard Keynes, by Giorgio La Malfa.

${ }^{2}$ During the correction phase of an unstable system, the link between the economy and the price system is usually one-way. The relationship between the economy and inflation (deflation) is always proceeding from the conjuncture (in deep depression during the financial crisis) to the falling prices. It is neither possible nor acceptable that there could be a feedback from the falling prices towards the economic conjuncture, which accentuates the economy depression. Prices are the image of the conjuncture situation and they follow her destiny in a neutral way, not being able to interfere in any way with the state of the economy. This absolute rule allows however an exception, as demonstrated during the ' 29 crisis. During the severe deflation following the Stock Market collapse and the financial crisis, the deep depression of the economy was accentuated and extended by the rigidity of Gold Standard Interwar (again adopted by the world's major economies after World War I). On that occasion, monetary rigidity has tragically accentuated the depression. This has created a vicious circle that is powered between the economy and deflation, tied to the economy, on one side, and between the fall in nominal prices, tied to the Gold Standard Interwar, and the economy, on the other side. A specific monetary factor (the monetary rigidity), which therefore made bidirectional the relationship between economy and deflation, relationship usually going one-way from the economy to the prices. An error that from the currency (linked to the Gold Standard Interwar) has moved sic et simpliciter to the economic level, thus inhibiting also the normal economy correction entrusted to the natural mechanism. Therefore, not only the monetary error has exhausted the economy for a ten-year period, but also blocked the natural correction action, so extending forward in time the system trouble fighting against an unsolved financial crisis. A perverse link that only dissolved when the (late) decision was taken by USA and European countries, to abandon the Gold Standard. A decision adopted by UK only in 1933, followed by the United States the year after. However, France resisted until 1935 because was strong the attraction of that country to the world gold movements and this assured in fact large gold reserves (G. A. Cossiga, 2017). 
tainability rules, requires the ability to listen to the aspirations of the community. And, even more, the ability to remove the widespread ambitions in the economy management, like to pretend to be able to overcome the limits imposed by the economy-nature relationship.

In a state of quiet and moderate management of the economy, first and foremost, it's necessary to listen to the prevailing orientations within the community. In fact, it must be strongly stated that the sentiment of a community is quite capable to express-in its majority-what the real condition of the economy may be. Not only that, because is also able to indicate, at least in its general lines, the path to follow to bring the economy back to the lost stable condition. Indeed, it should be argued that the proven ability of the community to have a reasonable idea of the economy general state is to be linked to the collective capacity to capture the negative signals (see for instance the price trends) that the markets send directly or indirectly.

So that the tendency of the economy towards recession uncovers the presence of errors in the management of economic systems and the consequent need for market activity to pause in search of stability and sustainable balance. We must therefore accept that this tendency to recession is somehow perceived by the community, which represents a sort of special terminal connecting humankind and nature.

We cannot in fact exclude that the natural law regulating the sustainable balance of economic systems has its own tools, which we have called natural correction system. An equipment that not only has the inductive force to cause the corrective recession but also is provided with alert warnings and signals to communicate the deviation of the economy from the stability path. Believing that the community is a sensitive terminal of this humanity-nature relationship, seems confirmed by the research on the collective sentiment about economy, market and consumption trends, orientation on saving use.

This is why even simply our neighbor has a vision quite clear on the economy condition, especially if things don't go well. At this point, it cannot be excluded that the community, understood as a large majority, would be able to discern between the strategies useful to resolve the economy swamped. It follows that the natural corrective procedure, intended as a tool to restore the stability of the altered systems, should be shared by the majority of a community.

Now, since the natural corrective system proceeds with pauses and slowdowns in the development mechanism for the economy rebalancing, it follows that the conjunctural tensions imposed to the correction system could and should be shared by the majority of a community. In other words, the community should be aware that the treatment requires a temporary pause of the economic growth and share, therefore a sort of resignation to wait that the restoring process would take place.

It's like saying that the concern of the leaderships who fear the consent collapse, due to the imminent or ongoing recession, could be out of place. In fact, also the community members would like to share the market's new horizon. In 
other words, it wouldn't be the eventual pace fall of natural development that would create imbalances in the political context, but rather the possible attribution of political responsibilities for the mistakes made in the past and the responsibility for the economic recession.

This is to say that a government facing the problems linked to the recession can maintain its justified consensus. Unlike then those leaderships who, surprised by the changing economic situation, are trying to do their best to put upward the cycle profile, because otherwise they would suffer a progressive loss of social acceptance. This is because inside the community's DNA there is the natural hope that tomorrow wouldn't be different from today, because the economy's growth follows a constant path without cyclical alterations. When the economy cycle is created, this means that the economy is already inside the instability sub-world. This fall involves the growth arrhythmias and a slowing or a pause of the development constant process, which instead belongs only to a balanced and sustainable economy.

These linear concepts involve the risk that at least some of the strategies to bring the altered cycle back to the desired pace, may be instruments that, in the end, could move in contrast with the natural orientation of the economy. In the sense that they could be developed to fight the recession trouble and its social consequences, identifying the economic malaise in the conjuncture and especially in the recession. Hypothesis, by the way, that sees evil in the result (decline of the economy), without going back to the real causes that led to the interruption of the development process.

Now, clearly the malaise is not in the symptoms, which are the conjuncture cycle and its involution, but in the cause: the instability of the economic system that derailed from the stability and sustainability path. Instead, we see attacked the symptoms of the disease, which in the end are the treatment autonomously self-inflicted by the system, to recover within possible times the path of stability and development, constant and gradual.

\subsection{We Have Tools to Contain the Recession Symptoms. But What Are the Effects on the Instability of the Systems?}

The long season of creeping deflation, which has become the common scenario of the global economy, holds the characteristic of a blocked or declining growth. ${ }^{3}$

${ }^{3}$ Incoming information since the last Governing Council meeting in early June indicates that, while further employment gains and increasing wages continue to underpin the resilience of the economy, softening global growth dynamics and weak international trade are still weighing on the euro area outlook. Moreover, the prolonged presence of uncertainties, related to geopolitical factors, the rising threat of protectionism and vulnerabilities in emerging markets, is dampening economic sentiment, notably in the manufacturing sector. In this environment, inflationary pressures remain muted and indicators of inflation expectations have declined. Therefore, a significant degree of monetary stimulus continues to be necessary to ensure that financial conditions remain very favorable and support the euro area expansion, the ongoing build-up of domestic price pressures and, thus, headline inflation developments over the medium term. Accordingly, the Governing Council adjusted its forward guidance on policy interest rates and underlined its determination to act if the medium-term inflation outlook continues to fall short of its aim. BCE, Economic Bulletin 8 August 2019. 
Even the great exceptions such as China and India are only apparently moving away from this common scenario, even if the economy growth, though declining, is still strong. Even in the United States, the inflation decline $e^{4}$-despite the repercussions on prices within the duties imposed by the White House-is a clear signal that the tension towards deflation is advancing and growing. It's inevitable that the price downward trend would be accompanied by a decline in development potentials.

Even in the USA, the aggressive policy of the White House has led to the choice of supporting the economic situation through a tax measure, approved in 2017 and entered into force in 2018, with the aim of cutting taxes that advantaged especially the privileged categories, but loading in this way the public debt. The attempt to force an economy that already grows over $2 \%$ with ultra-Keynesian maneuvers, can produce an anticipation of the cycle and therefore a drop of potential in the near future. ${ }^{5}$

As saying that the global economy travels towards a sort of homogenization of development or regression perspectives, as an unexpected outcome of the globalization long story. A long road that is bringing closer the economic conditions of the Western countries and the Asian continent and which today sees Africa as the new protagonist: the continent, late to the globalization appointment, is in fact reshaping the global economic landscape.

The long run of the economies of Southeast Asia and above all of China allows a reading of the globalization process, still in progress and not completed, as an inevitable evolution - which continues over time-of the harmonization process of the relationship between humanity and nature. A reading that therefore understands the harmonization of global development processes as a need moving in line with the nature evolution and that requires a greater synchronization of ${ }^{4}$ Inflation. Consumer price inflation, as measured by the 12 -month change in the price index for personal consumption expenditures, moved down from a little above the FOMC's objective of 2 percent in the middle of last year to a rate of 1.5 percent in May. The 12-month measure of inflation that excludes food and energy items (so-called core inflation), which historically has been a better indicator than the overall figure of where inflation will be in the future, was 1.6 percent in May down from a rate of 2 percent from a year ago. However, these year-over-year declines mainly reflect soft readings in the monthly price data earlier this year, which appear to reflect transitory influences. Survey-based measures of longer-run inflation expectations are little changed, while market-based measures of inflation compensation have declined recently to levels close to or below the low levels seen late last year. FED-Monetary Policy Report-July 2019.

${ }^{5}$ The largest effects on GDP over the decade stem from the tax act. In CBO's projections, it boosts the level of real GDP by an average of 0.7 percent and nonfarm payroll employment by an average of 0.9 million jobs over the 2018-2028 period ... In CBO's projections, real GDP expands by 3.3 percent this year and by 2.4 percent in 2019 (see Summary, Table 1). It grew by 2.6 percent last year. $C B O$ The Budget and Economic Outlook: 2018 to 2028-April 2018. Output. Real GDP is projected to grow by 2.3 percent in 2019 and by an average of 1.7 percent per year from 2020 through 2023 . Most of the growth of output in CBO's forecast over the next few years is driven by consumer spending and, to a lesser extent, business and residential investment and exports. Compared with the robust pace of output growth in 2018-3.1 percent, the fastest annual growth since 2005-output growth is projected to slow in 2019. That projected slowdown largely results from an anticipated slowdown in the growth of business fixed investment, as the positive effects of recent tax legislation on investment growth begin to wane, and from a sharp reduction in federal purchases starting in the fourth quarter of 2019 that would occur under current law. CBO The Budget and Economic Outlook: 2019 to 2023-January 2019. 
global development.

Also the globalization processes have evolved and are taking place without an apparent direction and are carried out outside the jurisdiction of states and governments. As saying that also the social aspects linked to the income distribution on a global scale are to be considered as factors that participate in the relationship linking humanity to the planet. In the sense that excessive deviations in the income distribution within a community or even at a global level are to be considered as phenomena adverse to the correct relationship between humanity and nature and, therefore, an important signal that the development line has taken the road towards the instability sub-world.

It's like saying that the social and economic evolution of human communities follows, according to times uncoordinated with those of one or more generations, a development trend coordinated instead with the evolution of our natural environment. So that with the globalization of social and economic development, is reduced the fragmentation of the economic events and the evolutionary process is increasingly played on global landscapes or is anyway moving in this direction.

On the other hand, we must admit that the trend towards the stability of economic systems has allowed the growth and evolution of humankind, despite thousands of calamities and adversities throughout the history. Therefore, we must admit also that the force pushing towards the stability is linked to the sustainability relationship between humanity and nature. Moreover, it also seems unavoidable that the exit from the stability relationship would involve a series of penalties, which are essentially the natural tools to promote the return of an altered system to its stable condition. The stability path offers the advantage of the constant and gradual growth, in accordance with the sustainability. Leaving the circuit of stability would change the development landscape, which would move within a sub-world of instability, different and unrelated to the stability world.

The current global landscape, pervaded by the tendency to price deflation and by a fall in development potential, confirms that the single and global economies have been traveling for some time within an unstable context, and that the conjuncture cycle therefore tends to the recession, in order to fight the errors responsible of the economy deviation. The normal reaction in this context is to use all the tools of fiscal and monetary policy to curb the phenomenon and to reinvigorate the weak economy. Now, there is no doubt that the goal to reinforce the pale economy is certainly acceptable. On the other hand, in the human DNA there is the idea that tomorrow could be not so different from today, precisely because the stable condition guarantees a linear and stable growth.

The problem therefore concerns what to do to achieve this shared goal. To answer this question, it's necessary to evaluate carefully the dangers related to the current condition of tendential deflation. This stage is reached when the instability has become chronic, that is it lasted a long time. In today's world, we shouldn't forget that just a decade ago a speculative bubble burst, not so different from that of '29, which caused a heavy financial crisis extended to the entire 
global economy. The apparent exclusions concerned, by the way, China where there was only a drop in an outstanding development rate. China at the time of the speculative storm was seen as a sort of free zone, with the result of accelerating the globalization to the benefit of the developing areas inside the Asian continent.

The issue to be examined is that in the aftermath of the 2008 great crisis, the industrialized world and gradually also the other players fell into the grip of the deflation tendency and the economy development opacity. The response to the extraordinary and partially unexpected event of the great financial crisis has been somewhat customary. In other words, the defenses offered by fiscal and monetary policy have been mobilized to control at least partially the great tsunami started by the crisis. Most industrialized countries have initiated ultra-Keynesian policies, above all to reduce the cascade-effect that the crisis triggered within commercial industrial activities and (firstly) to recapitalize the large banks that were facing a possible bankruptcy.

We should say that faced with the danger of a global recession like the one experienced in the 1930s, the use of exceptional measures in terms of size and quantity to mitigate the effects of the crisis was an inevitable necessity. However, it cannot be overlooked that though the exceptional dimension of the interventions has given appreciable and necessary results, nevertheless has been actually interrupted the natural corrective action that we can presume is basic for the speculation-financial crisis paradigm.

We can talk a lot about the multiplier effect that the financial crisis produces and goes far beyond the recessive wave induced by the correction. The recession in fact has the mere purpose to give a pause to the economy, in order to bring the economic system back on the stability path. Having made this distinction between the natural correction and the cascade-drop of excess activity due to the falling equilibrium, it appears even more evident the urgency to contain the crisis excesses not motivated by structural factors.

However, the fact remains that the trouble provoked ten years ago by the financial tsunami has implemented and increased the response on the front of active policies, so limiting however the expected effects of the curative recession. The problem now is not so much to discriminate between the quantum of active policies useful to contain but not to contrast the cure and the quantum that acted instead in opposition. The problem is to assess whether at present there are symptoms that the correction of the global economy instability has been insufficient and that, therefore, we could expect new events like those experienced during the first decade of the 2000s.

Now, the instability state inside the global economy has not been solved and the main symptom is the deflation tendency that is gripping the current economy. This deflation tendency can be used as a sort of thermometer in the economic condition precariousness, so that the declining prices are more significant in the countries most exposed to the economic turnaround, as in the case of the Europe of Euro area. However, even the United States, which is traveling at a 
rate of $2 \%$ of GDP growth (but decreasing next year), is witnessing an unexpected (though not so much) inflation, well below the "magic" number close to $2 \%{ }^{6}$ The phenomenon is not absent even in China, despite the support to the economy growth that travels in fact around 6\%.

As can be seen from Figure 1, the phenomenon of deflation tendency in economic systems is global. The signal of the drop in the inflation rate is more evident for countries and continents that are experiencing a greater financial fragility, such as some countries in Mediterranean Europe and Southeast Asia, including Japan. It's interesting to note that the inflation eclipse was merciless during the recent financial crisis, thus marking a sharp negative price rate. In the post-financial crisis, the inflation rate then began to re-emerge, always remaining in a range between $0 \%$ and $2 \%$, despite the up and down of international prices, especially for oil, and the geopolitical events in the Middle East. The curve now tends to contract again, essentially in the countries most exposed to financial risk.

\subsection{The Monetary Policy Is under Siege. Why?}

Even in Trump's America there is a decline in the inflation curve, even more worrying in a country that implemented a tax reform since 2018 and dragged the public debt to over $100 \%$ of GDP. Unfortunately, once again favoring an income distribution less equitable and far from solidarity. An inflation trend against the economy's main variables, which are traveling at the highest levels of the period.
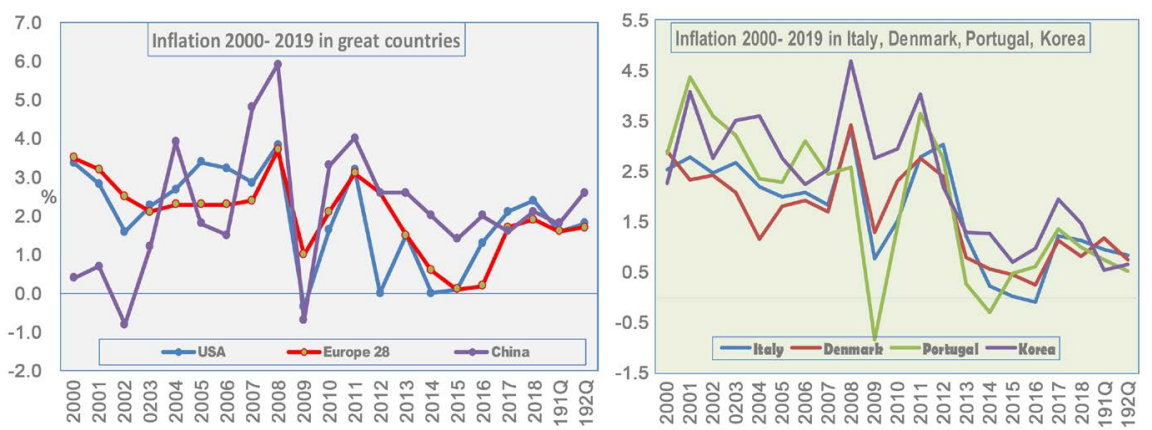

Figure 1. (a) Inflation 2000-2019 in great countries; (b) Inflation 2000-2019 in Italy, Denmark, Portugal, Korea. Source: Elaborations on OECD and IMF data.

\footnotetext{
${ }^{6}$ Information received since the Federal Open Market Committee met in June indicates that the labor market remains strong and that economic activity has been rising at a moderate rate. Job gains have been solid, on average, in recent months, and the unemployment rate has remained low. Although growth of household spending has picked up from earlier in the year, growth of business fixed investment has been soft. On a 12-month basis, overall inflation and inflation for items other than food and energy are running below 2 percent. Market-based measures of inflation compensation remain low; survey-based measures of longer-term inflation expectations are little changed. Consistent with its statutory mandate, the Committee seeks to foster maximum employment and price stability. In light of the implications of global developments for the economic outlook as well as muted inflation pressures, the Committee decided to lower the target range for the federal funds rate to 2 to $2-1 / 4$ percent. This action supports the Committee's view that sustained expansion of economic activity, strong labor market conditions, and inflation near the Committee's symmetric 2 percent objective are the most likely outcomes, but uncertainties about this outlook remain. Federal Reserve issues FOMC statement-July31, 2019.
} 
In this context, the FED decision-during the meeting held on 31 July last-to reverse the US monetary policy direction, and also to lower the target range for the federal funds rate until 2 to 2-1/4 percent, has created some perplexities specifically because of the obvious imbalance between the good (only apparent?) economic trend and the decision to give anyway a sign about the cost of money.

On the issue of the potential influence of political choices on Federal Reserve decisions, the previous governors of the Central Bank Board made their point. With a note signed by Bernanke, Yellen, Greenspan and Volker [2], the former governors feared the potential political interference with the Central Bank's deliberative process. ${ }^{7}$

Apart from the issues related to the Central Bank's independence, the controversy raised by the decision of the FED on July 31st shows at least that the symptoms offered by inflation on the prospects of the economy are partially reduced, to the advantage of values expressed by the GDP and unemployment trend. I would say that this inattention is not a good symptom, because the prevailing characteristic of the 2000s great financial crisis was the sudden drop in prices that then turned to be negative.

The tsunami affecting prices is certainly the sign that the crisis could be wide and would still act on the financial front. Therefore, we cannot underestimate the importance that the hyper-financialization of the economy can have in the near future. The deflation-finance combination is the point of view from which it's necessary to look at the current situation to assess the risks deriving, by the way, from the constant tendency of the economy to deflation and, at the same time, from the enormous growth of financial wealth (and of global debt). A financial wealth growth that is increasingly incompatible with the resources of real economy.

From this point of view, the dangers of the excessive financialization of the economy should have suggested monetary policies oriented towards caution and control of excesses. The problem in fact is not to maximize the potentials of the economy with the active support of monetary policy, but rather to control a disorderly growth, which is fed by the liquidity excess and the credit generosity far beyond the economy's actual capability. From this point of view, the possible option for monetary policy wouldn't be to lighten the money cost and above all to stop the reduction program, increasing in perspective, of the Central Bank assets.

A possible decision not to follow the accommodating trend required by the market "is in accordance with its mandate from Congress: to promote maximum employment, stable prices, and moderate long-term interest rates in the U.S.

${ }^{7}$ As former chairs of the Federal Reserve Governors' board, we are united in the belief that the Fed and its president should be allowed to act independently and in the best interests of the economy, free from short-term political pressures and, in particular, without the threat of removal or demotion for political reasons ... History has repeatedly taught that an economy is stronger and works better when the Central Bank acts independently of short-term political pressures and relies solely on sound economic principles and data. America Needs an Independent Fed From. Wall Street Journal-August 5. 2019. 
economy" (not so different from the mandate of the European Central Bank and of the main Central Banks). First of all, because it wouldn't be a task of monetary policy to stimulate the markets' growth, but rather to ensure a compatible (sustainable) growth to the economy in the medium term. The attention of monetary policy shouldn't be aimed to support short-term benefits, but rather to guide the economy's course towards a stable and constant growth over time.

In other words, the monetary policy makes autonomy to be its flag in order to play a complementary and moderating role with respect to the political maneuvers promoted by governments. In some ways, therefore, the Central Banks look to the medium-long term even diverging from the politics of the governments in daily life, always struggling with the problems of consensus and acceptance of their economic management programs.

That said, the deflation tendency, which becomes stronger over time, essentially confirms that the great financial crisis of the 2000s first decade has left a poisoned tail: the economy weakness and the recession tendency. These are more direct symptoms that the instability of the systems has not been overcome and that the natural corrective mechanism is still working. How to reduce the risks of a future spread of a new financial crisis, while a speculative climate is recharging again? This is the current issue that monetary policy has to deal with, even dissenting from the demands of leadership governing the economy.

Well, the 2008-2010 financial crisis was, at least in part, mitigated through heavy ultra-Keynesian interventions. Since the recession is to be considered a treatment to reduce the deviations from the stability path, we must admit that the start of the "unreasonable excitement-financial crisis" paradigm is to be considered an alternative system when the roads leading to a corrective recession are precluded.

In other words, the uncertain battle against inflation, in a world still suffering for instability, has been the reason why the deflation appeared on the world scene. Well, the creeping tendency to deflation should be considered a tool of natural correction to contain the persistent instability. This remedy does not seem to be understood in its intrinsic quality. The deflation, by the way, is not an inflation's companion and they cannot exist together.

However, just like inflation, the deflation is a signal and a promoter of correction, to bring back an altered economic system on the stability and sustainability path. It is inexorable that, when this monetary signal appears, the economy would give signs of weakness so tending gradually to contract. Consequently, the appropriate action in terms of economy sustainability is certainly to let the conjuncture cycle perform its corrective function.

We can add that the laissez-faire is certainly costly at a social level, so it's necessary that the public budget would get the appointment with the cycle correction with enough resources reserved for interventions-even in deficit-to contain and mitigate the inevitable damages due to the income decline and rising unemployment. A function of economy management, therefore, inspired by moderation, with a view to the medium-long term and to the protection of dis- 
advantaged minorities, which are most affected by the economic reversal.

At this point we can make some observations on the potential behavior of the economic system when the recession path is partially precluded. We have already observed that the persistence of inflation is somewhat put in a corner with a policy of support to conjuncture partly offset by a less accommodating monetary policy. This could lead to a stalemate that could turn over time the economy towards deflation. All this would happen if the long struggle against inflation (see the eighties) didn't solve the instability problem, which is the cause of inflation. An unstable condition, matured in the seventies, which has not been eradicated by the contradictory mix of a permissive fiscal policy and a less accommodating monetary policy. The natural correction system therefore seems to change strategy and follows the way out offered by the inflation decline, so falling towards negative or almost negative values.

At the deflation stage, which is the prevailing condition afflicting today the global economy, there remains the problem of accompanying the altered system towards a controlled recession, which would help the economy to find again the stability path and a constant and gradual growth. Now, it could happen, and indeed it happened, that this opportunity to find again the natural correction path, would be barred or made anyway difficult by the political intervention, which sees the recession as the nightmare driving consensus away from government and leadership.

Well, we can certainly understand that the recourse to public budget is in the faculties of the leadership and that another re-proposal of ultra-Keynesian measures is part of the normal package of resources available. Yet this resource can become anything but convenient. Because with the public debt increase, as soon as this reaches and exceeds $90 \%-100 \%$ in terms of GDP, the expected results of relief of the weak economic conjuncture are of no value or just temporary. Especially when the system is already under the deflation hard grip. It is surprising that the stainless confidence in the merits of ultra-Keynesian measures wouldn't be placed at this point in a sort of past memories' shelf!

The fact that the widespread use of ultra-Keynesian interventions has achieved some good results to mitigate the harshness of the 2008-2010 financial crisis, does not detract from this last observation. As a result of the massive intervention of public budget at the time, the majority of the most advanced countries now suffer from the suffocating weight of public debt, which on average exceeded $100 \%$ in terms of GDP. On the other hand, we should note that a heavy public and private indebtedness is causing the economy degradation towards deflation. Then every action using public resources, is only worsening the economy trend. That is, it's only further oil poured on the fire ...

The problem remains, therefore, of the unstable economic system reaction, if it doesn't find the way open towards the controlled recession. At this point it should be noted that any exhaustion of the usual fiscal policy interventions obviously would increase the focus on monetary policy behavior. As we have said, the issue of a monetary policy independent from the government's position 
about economy is of substantial importance. In fact, starting from this assumption, the monetary policy cannot be a mere instrument of support for the conjuncture to be used when are lacking the resources available to the economy management.

The monetary policy cannot and shouldn't be a sort of maid of the government policy but should support instead a political vision covering the range from medium to long term, and not just the short period. The function of the Central Bank can be described somehow as the guardian of the stability of economic systems and guarantor of the economy development sustainability.

From this point of view, it's clear that the Central Bank must act like Ulysses, plugging his ears against the siren song of governments and of markets always asking for new liquidity. The ultimate goal of economic policy is therefore to listen to the community's voice that-at least in its majority-can be considered a sort of sensible economy thermometer and a terminal of the implacable stability tendency that is inside the economy's DNA.

\subsection{The Monetary Policy Is Not a Guide But Should Correct the Markets}

Paul Volker, appointed on July 25, 1979 as chairman of the Board of Governors of the Federal Reserve System and confirmed in the second round in 1983, to disarm rapidly the rising inflation did not hesitate to raise the federal funds rate, which averaged $11.2 \%$ in 1979 , to a peak of $20 \%$ in June 1981 . The combination of the Fed's tight money policies and the expansive fiscal policy of the Reagan Administration (large tax cuts and a major increase in military spending) produced large federal budget deficits and significant macroeconomic imbalances in the US economy. After the severe recession of 1980-1982, the US economy recorded a decade of sustained growth, $3.5 \%$, on average also seizing the opportunity of the oil counter-shock in the 1980s.

Basically, the incongruity between the abruptly restrictive monetary policy and the accommodating fiscal policy has conspired causing a recessive trouble for the US inflationary economy during the early 1980s, thus playing the role of the natural correction. An exemplary case of monetary policy that ranged over the medium-long term, thus gaining a broad consensus and an undoubted result also at the economic level.

It must be said that monetary policy shouldn't have any implication with the economy development. First of all, because an economy moving within sustainability field follows a line of constant and linear development. Moreover, the monetary policy must supervise the correction and control process of economy, as it doesn't have among its goals the economy support, which is synonymous with instability and balance seeking.

Going back to the global economy context, the tendency towards deflation is accentuated by the high public debt burden, which strains the public finance. Ergo any attempt to support the cycle with Keynesian maneuvers essentially aggravates the monetary problem. On the other hand, once closed the door to oth- 
er maybe winning options of fiscal policy in managing the economy, the markets strongly appeal to the monetary policy responsible to make them play the unusual role of economy managers. At this point, the adjustments in the cost of money to make the credit option and the new liquidity more available through the announced reopening of the QE or even by the block of the Central Bank's asset reduction program are pretending to be substitutes for the function of economy management. In place of or in addition to resources available for the government function to support the economic cycle.

The problem could be exactly the willingness of the Central Banks to make actions in order to stop the slowdown in the economic cycle. At this point could be configured a new obstacle to the natural correction, to which in fact is precluded the corrective recession path within the altered economic systems. The economic picture therefore denounces a growing development difficulty, which becomes increasingly creeping, while is intensified the tendency to deflation in the economy. What are the developments in such a situation, briefly outlined and that closely recalls the present global economy?

A potential answer comes from the experience we have lived during the first decade. Even at the time, the prevailing signal was the moderate or declining inflation. A signal that obviously was conflicting with the gradual but constant turnaround for an unmotivated and unstoppable development of some sectors, running without any connection with the real economy. It can be argued that the stubborn closure to the corrective recession option and the political synergies have at least partly hindered the way to a healthy economic decline. Therefore, these may have been the premises to start the speculative turnaround.

As saying that the speculative bubble of the last decade was essentially a sort of exceptional response to the delay in the recession course, contained as a sort of economy nightmare to be absolutely blocked. In other words, the tendency to price deflation can therefore be interpreted as a sign of a potential near recession. If this corrective action is somehow delayed and postponed, a new potential enemy may appear on the economy's horizon. Elusive and ambiguous, because tensions would arise in certain sectors of the economy, though without valid reasons to justify them.

The system seems to be acting somewhat in the wrong direction. From the inertia and weakness state accompanying the tendential deflation, we pass abruptly, at least in some sectors, to a progressive acceleration without any valid motivation, also for the rapid change of perspectives. The speculative tension would therefore be a sort of reaction, indirect and natural, to the obstacles placed in the system instability corrective process, when the instability would be prolonged in time and there wouldn't be any sign of a turnaround.

At this point it's evident that a routine recession, which can periodically appear due to an exit from the stability path, is mistaken for an Armageddon of the economy! And this for the usual crazy desire to make the economy run beyond its potential, which is objectively impossible. Because the present acceleration will be paid with the future deceleration and recession. In short, the scrupulous 
and intransigent denial to suffer the consequences for the entry into the instability sub-world, can be the cause of a great tsunami in the economy, due to the collapse and annihilation of all the virtual developments triggered by speculation. A tsunami that would carry with it not only the natural correction of the unstable system but also all the ballast created by the absurd process of irrational speculation. The terrible wave of the post-speculation super-financial crisis would therefore be an excess not only just announced but also caused and triggered by the behavior of policy managers.

The ultra-Keynesian response given during the evolution of the 2008-2010 financial crisis was certainly necessary to correct the negative outcomes of the super-correction, but it is also the obvious symptom of a standard behavior. That is, the use and abuse of cycle correction tools through fiscal and monetary policies.

That's why, during the formation phase of the hyper-speculative cycle, we must carefully observe the behavior of monetary policy and, above all, the deriving consequences in terms of money cost and new currency creation. Because during the hyper-speculative phase there is the anomaly of an almost normal economic growth of around $2 \%$. This would suggest a normal growth trend, basically, without any concern. Nevertheless, it isn't normal at all, and in fact it's a totally abnormal bluff. It follows that in these extraordinary circumstances, an accommodating policy made with low money cost and wide monetary availability could create the basis for accelerating and emphasizing the speculative crisis, which is now overheating the markets.

I would just like to consider that once the basic conditions for speculative acceleration are started by means of a very accommodating monetary policy, even a slowdown (but too late) in terms of block for interest rates and currency could not be enough to contain the development of the speculative emphasis. Because the speculative mechanism itself would be able to accelerate the money speed and to maintain exuberance.

\section{The Policies to Control Instability Could Instead Just Delay the Solution of the Economic Problems}

\subsection{The Tensions Running through the Economy Appear Once Again Repressed}

The tensions in the economy seem once again repressed. In the sense that the apparent market health, despite the troubles of the hegemonic policy in Trump's America, can be misleading and could hide the unstable market state, unresolved after the 2008-2010 financial crisis. It must be said that an apparent calm within the markets is the foggy dreamlike scenario created with the birth or the development of a speculative tension. In an atmosphere somehow narcotized by the speculative fumus, a collective undervaluation takes the shape which can justify the apathy and the strange presumption involving also the operators.

Well, in a context so altered, a decisive contribution to the persistence of the quiet expectation feeling can come unexpectedly from the Central Banks and 
from monetary policy. In this regard, it's to be considered that in the current climate the main instability symptom is given by the declining inflation rate. A mechanism that overloads the concern about the damage caused by deflation, mainly due to the difficulty of fighting it with the monetary tools available to the Central Banks. All this creates within the market a tension tending to stifle the symptom of malaise (deflation) rather than to fight it.

Now it's clear that to silence the general and immediate source of information on the economy state, what basically are the nominal prices, is different than to remove from the economic scenario the underlying reasons causing the regression of inflation. Looking at the current scenario, an aggressive monetary policy pushing the money cost down until the zero level, and promoting at the same time the creation of new money, can contain and partly remove the symptom of declining prices. But the basic problem, namely the instability promoting the slow fall in prices, remains untouched despite the good reaction of the markets.

The great liquidity availability accompanied by deflationary phenomena creates not only the negative result of underestimating the real economy state, due to the fictitious drop of the deflation symptom. But it also produces the consequence to resolve, though just apparently and temporarily, the difficulties linked to the decline of nominal prices (Figure 2).

Deflation, instead, if allowed to act, tends to depress the credit upward trend, because the debt increase over time worries operators and families. The return to positive values of the inflation rate essentially eliminates this concern and, instead, stimulates the search for new credit, being so low the money cost.

In other words, the extraordinary instruments of monetary policy, such as the Quantitative Easing, can become the hidden mediators of that feeling of apparent calm stagnating within the markets during the formation of a speculative

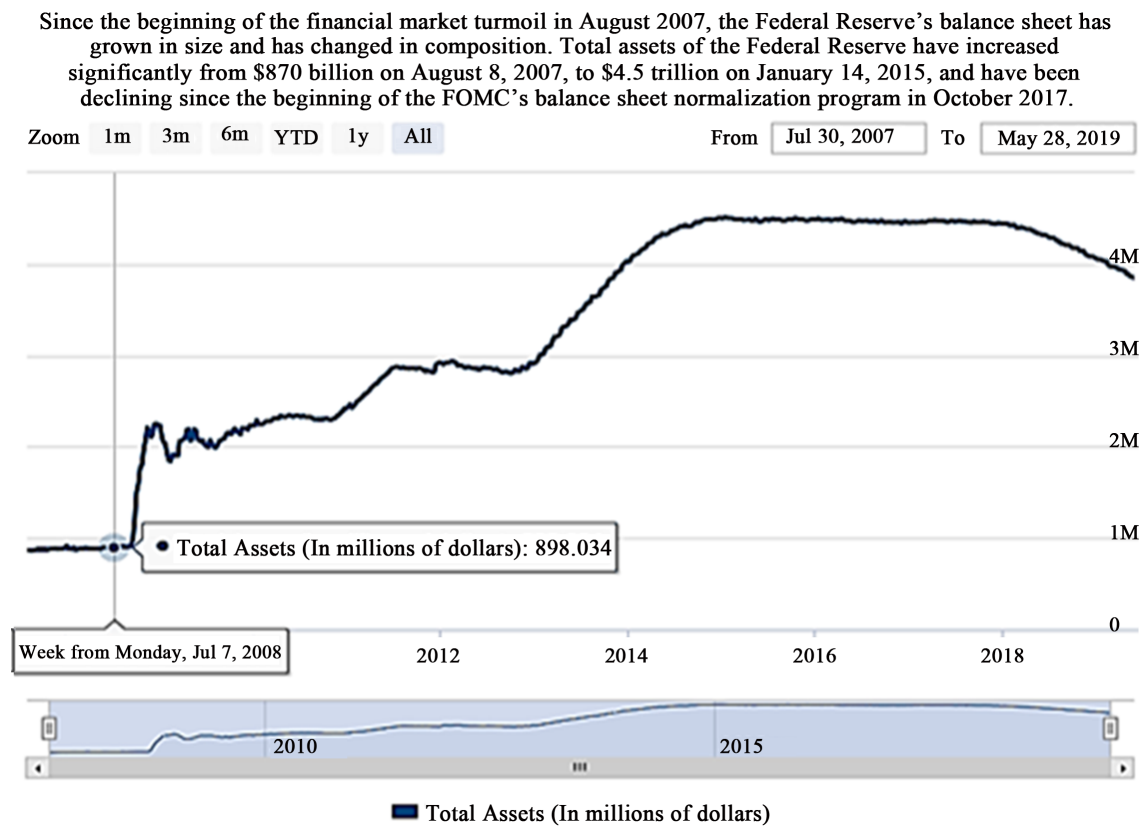

Figure 2. FED: Recent balance sheet trends. 
bubble. At the same time, they can become instruments to promote cheap credit which, in turn, is the tool that can fuel the expansion of the speculative bubble.

Facing inflation, the monetary policy is pushing interest rates upwards. Therefore, it moves in harmony with the natural correction maneuver that always aims to promote the return of the altered economy to stability. Even in the case of an inflationary economy, the monetary policy doesn't appear able to play an active role in the recovery process. But at least it's moving in the wake of the natural correction program, with the interest rate increase which in turn contains the inflation emphasis.

Differently, in case of deflation the monetary policy is not called to play an active role to promote development; however, there is a real risk that it would boost the virtual economy that is moving and growing, so that over time it could fuel a speculative bubble. The problem is the closed door against the attempt to reverse the economic cycle, continuously offered by the natural correction but unsuccessfully. In this referral game, unfortunately there is the serious risk that the irrational quid loaded by the speculation time clock would not only remain unresolved but could instead be loaded again. Because the stability trend for economic systems imposes to the economic systems, though gradually and flexibly, to converge towards a stable sustainability structure. Therefore, if we do not reduce the control over the natural mechanism of the economic cycle, the prospect of a new post-speculation financial crisis will become quite strong (Figure 3).

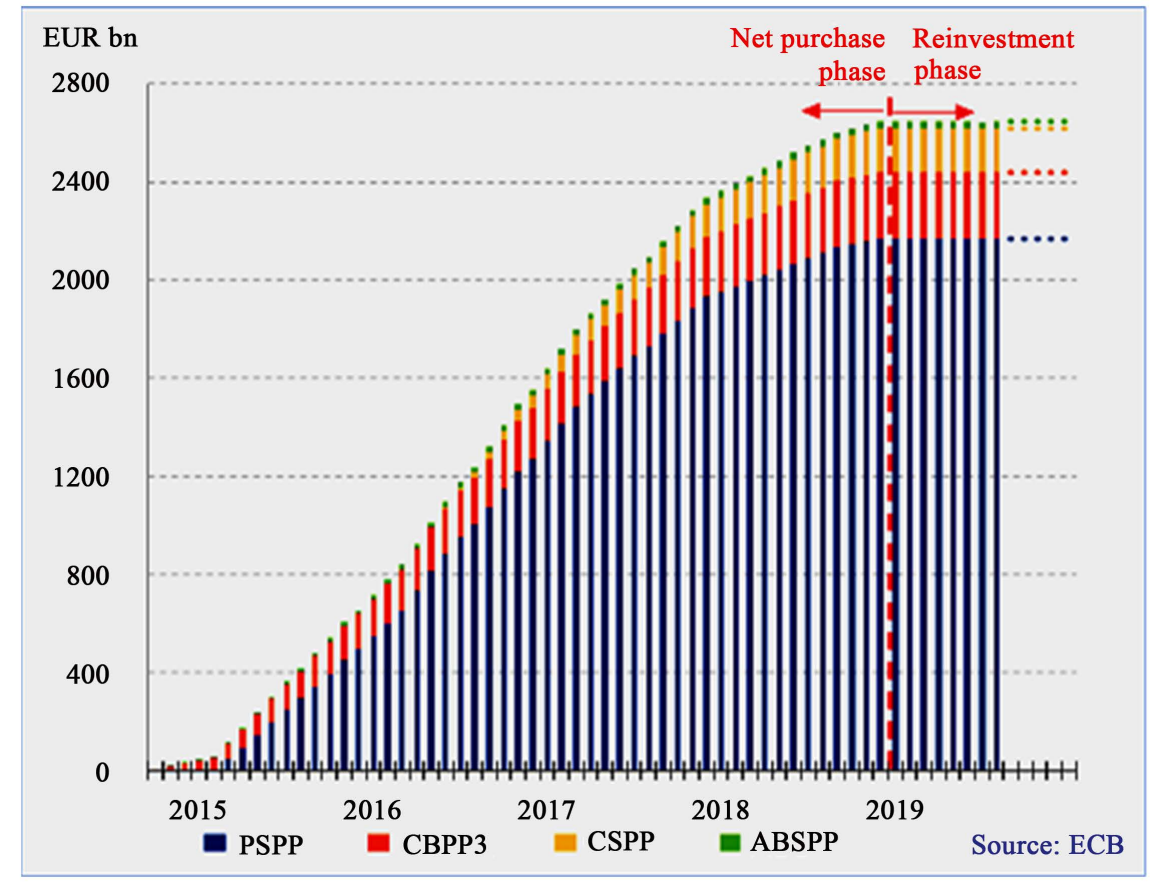

Figure 3. BCE Reinvestment phase of the asset purchase program. Corporate Sector purchase programme (CSPP); Public Sector purchase programme (PSPP); Asset-backed Securities purchase programme (ABSPP); Covered Bond third purchase programme (CBPP3). 
It can be deduced that any claim of monetary policy to have a decisive role in the process of developing economic systems, must be abandoned. Because the role of monetary policy is not to give impulses, but rather to put the economic systems back on the sustainable development path. From this point of view, the maneuver should measure some possible steps to reduce interest rates; rates that, in any case, should never become negatives in real terms. In the event of a prolonged tendency to deflation then, the decrease of rates, wherever applied, should never lead to key interest rates lower than $2 \%$.

In fact, we should consider that the equilibrium rate for the inflation sample accepted by the Central Banks, is close to $2 \%$. An exact measure of the base rate is unlikely because it's just an ideal measure. In fact this is the value that nominal prices can assume when the economy would have long been in conditions of stability and sustainability with the natural world around us.

It's therefore a measure that can be just touched but not achieved, because the conditions of economic stability over time are still a sort of utopia. Therefore, when the inflation rate has reached or is approaching the decisive $2 \%$ share, we can only say that we are still struggling with deflation, partly because its expression is partly suffocated by an overly accommodating monetary policy.

We may also add that the rate close to $2 \%$ is the measure of a stable economy, which is therefore not subject to changes in inflation and jumps in the economic cycle. An ideal condition of an economy constantly developing and growing, which therefore does not register variations in prices, except those produced by the economy's movement itself. In fact, a rate close to zero in the price movement would make no sense. Because the rhythm of the economy-though constant-must somehow be reflected like a sort of echo on the economic activity register.

Therefore, if the conditions of the economy would recommend a drop in interest rates to give a boost to production, the drop in the reference rates of the Central Banks should not fall below the base rate close to $2 \%$. A drop in interest rates that would be projected even below this lower limit could take, indeed, the meaning of an economic policy intervention indirectly supporting the credit and the conjuncture. That is, in this case the monetary policy would tend to overlap with the fiscal support policy aimed to contrast the economic crisis [3].

As already said, the economic conjuncture with its growing rhythms is not a character of the stable economy but is a tool to correct the instability of economic systems. If the correction process would take place at its own natural pace, we should see a gradual return to a stable steady growth of the sustainable economy.

The problem, however, is complicated by the delays suffered by the corrective motion, so that the anomalies imposed by the instability sub-world are multiplied. As in the case of the tendency to deflation, which is not recognized as a sign of a malaise calling for a recession, although it's a symptom of adjustment and pause of the exhausted system. Instead, it's prevailing the urgency to avoid the social troubles created by the recession and therefore to support the economic 
policy, which would act as a sort of crutch for the economic cycle. Mistaking signals, such as deflation, understood as instruments of the expected recession (though deflation is and remains just a signal) is the cause of an activism of monetary policy, which contrasts with the actual nature of an intervention made on the money behavior.

But money is a "transparent body" in the economy running. It participates to the economic affair just as a handmaid, and it is a symbol easing the economic activity course. If the monetary policy moves so much to finally interfere with the functioning of the economy mechanism, then we have the basic conditions on which could start a speculative crisis and the development of its irresponsible paradigm.

\subsection{The Paradox of the Ultra-Accommodating Monetary Policy}

Well, since the money is a "transparent" instrument of the economic affair, it shouldn't in any case enter as a protagonist in the competition, especially when the tendency towards deflation is accompanied by an economy in recession.

It seems reasonable to believe that the tensions started inside the markets when the tendency to deflation becomes stronger, may represent a motivation for the Central Banks to ratify a progressive decline in the main reference rates, until they reach and even go below the base rate of $2 \%$. In this case, as already mentioned, the distance separating the zero from the basic equilibrium rate is occupied by the background noise created by the economic activity. We are therefore within a border area, in which there isn't a real price movement but only a sort of resonance produced just by the economic motion [4].

It follows that should the monetary policy decides to proceed beyond this border and to lower the reference rates to almost zero, the action of the Central Banks would lose its function as market regulator and balancer and then would enter into an unknown territory.

The attempt-it's quite obvious-is to support the weakness of prices, on the assumption that the money cost drop, even to the point of becoming negative, could in some way emphasize and reinvigorate prices. However, this is an attempt relying on the idea that we can challenge the image instead of the real subject, that is, that we could directly attack the exhausting deflation by balancing it with a progressive decline in the money cost.

As already said, the deflation is a symptom of the economy malaise and not its cause. On the other hand, it's certainly no accident that the evil symptom, the image of the economy instability, is reflected precisely in the currency which, as we said, is in turn the image of the economy affair. An image in which all its anomalies are reflected, without being part in any way of the continuous motion of the economic system.

It follows that the interest rate fight against deflation can be a weak weapon; therefore, we cannot expect any real advantage from this défaillance of the money cost. But not only that. Because an extremely low money cost is an alteration of the market rules, which can occur only if the conditions for a liquidity 
excess had been created and there would be therefore a strong willingness to credit and indebtedness. In other words, it would be the market conditions, with a great liquidity availability and debt readiness, the basis on which the conditions are created for a further drop of the key interest rates adopted by the Central Banks.

It would somehow seem that what is facilitating the decline in key interest rates, are not only the values of the balance base rate, but also and above all the market condition, which draws on the large liquidity excess and credit availability to make credible the operation. In other words, the market shows that it's hungry for more liquidity and new credit to revive the weak economy and the lethargic prices. A sort of strategy to support the hypothesis that an aid at the level of money cost, could achieve the expected result for the economy recovery. Now it seems clear that, in these conditions, any successful possibility would be unlikely.

However, it's necessary to distinguish. Because the forcing of a pro-cyclical monetary policy may not simply give the expected effects in terms of rising economic cycle and inflation recovery. But it could also start a sick development, inconsistent on the real level of the economy. In other words, two outcomes can be presumed for an endless drop in the key interest rates of the Central Banks. The simplest and less alarming is an inconsistent response, in the sense of a stagnant inflation even after a temporary rise. Equally on the economic side that could maybe avoid a tightening of the declining economic cycle.

The second outcome is more intriguing. In fact, the market's response to a further decrease in the money cost may meanwhile have the effect to revitalize the stock exchanges, which applaud to the new credit and speculation possibilities offered by the ultra-accommodating monetary policy. Let us note that the decision not to allow other maneuvers on interest rates, which are already low, may cause a negative market reaction and a sharp fall in stock market prices. This reaction is certainly not positive because it testifies that the development circuit is distorted and relies on the liquidity availability and on credit opportunities. In other words, we are facing a market blocked in almost recessive conditions.

Under these conditions now, subsidizing the already excited market with monetary policy instruments can only mean that poor growth and weak prices are in any case linked to the ultra-accommodating conditions of monetary policy. It follows that even this minimal trend cannot be maintained over time.

However, we should also consider that the natural corrective system always remains in search of a way to put the economy again into the stability and sustainability area. From this point of view, we should admit that any downward pressure on the key reference rates of the Central Banks doesn't seem able to reduce and contain the system instability and, at best, it can only prolong the status quo.

Therefore, it's quite evident that the correction system remains in search of balance, even if the reaction times would be long or probably very long. Howev- 
er, staying within the positive hypothesis, the system's reaction to a possible new downward correction of interest rates will be most probably bland or inconsistent. In this case, we could have a prolonged instability of economic system that, moreover, would be facing the economy weak growth and the tired prices.

The problems can get complicated, by the way, if the economy thermometer marks an expected, though unlikely, revival of the economic cycle. We cannot hope for a positive final result, because the unstable state of the economic system doesn't allow this hypothesis to get real. Therefore, if we have an improvement in the economic climate, it may not be good news. In the instability sub-world, it's not expected a vibrant economic cycle, because the goal is the gradual fall into recession in order to recover the stability natural state. Therefore, we have to think that the new unexpected vivacity is just how the sub-world expresses its search for a way out of protracted instability.

The symptoms of this new reality, no longer positive, are therefore not only a renewed apparent strength of the economy, but also an intensification of the market dependence on aid requested from politics with increasing intensity. As already said, the dark side of monetary policy, in the shadow of deflation, is given by the danger represented by the decline in interest rates, especially if they go next to lowest until zero level. In this perspective, the disincentive to credit and debt created by the deflation fear is annihilated (Figure 4).

With the cost of money falling to the minimum and approaching the zero level, become stronger the temptation to increase the debt position in order to participate in the apparent market upturn. The result of this injection of confidence in the prospects is a gradual increase in the market tension, which shows a

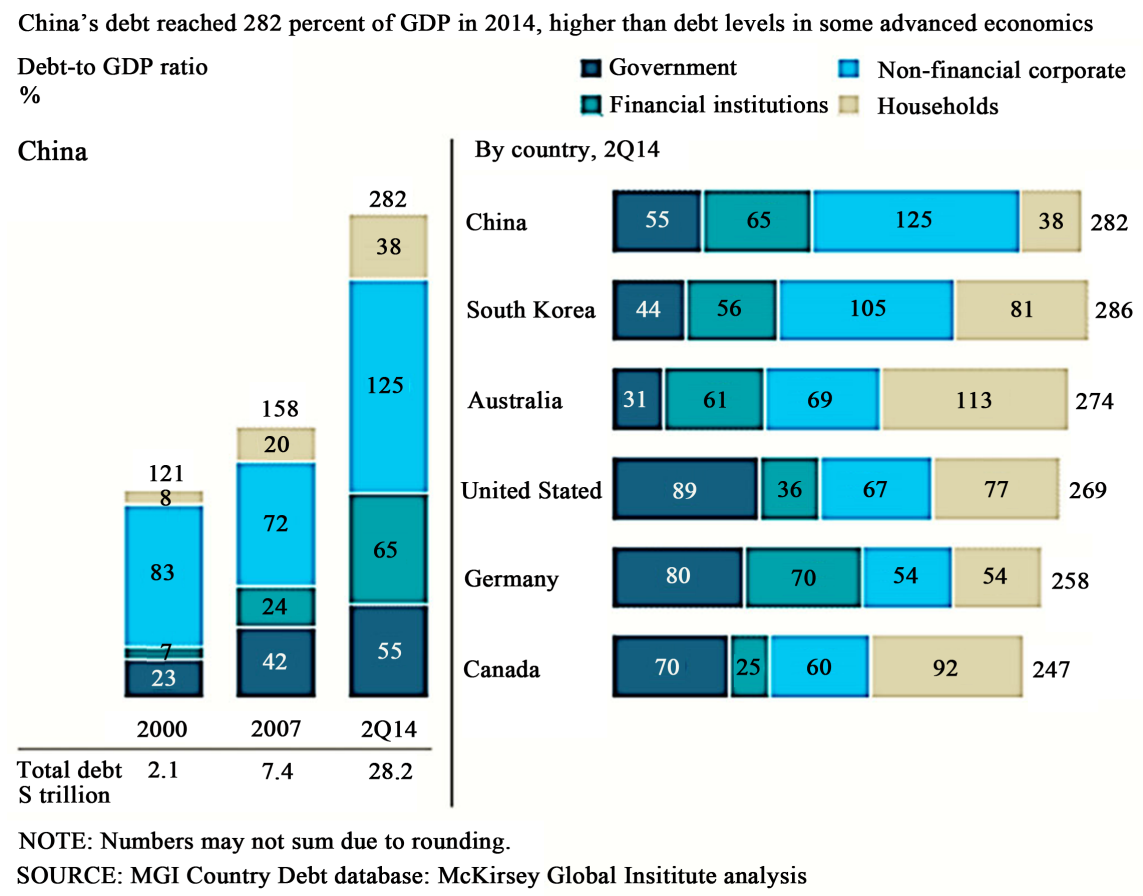

Figure 4. Debt in percentage of GDP for China and for some advanced countries. 
sort of discontinuity. In the sense that the dynamic deriving from speculative tension doesn't spread in all directions but focuses only in some large sectors. During the previous speculative crisis, in the second half of the last decade, the Real Estate sector was the environment in which the worst financial crisis since ' 29 was smouldered and developed.

Now, in the case of a tendency to global deflation, the growing debt phenomenon can spread if all the conditions promoting growth are aligned, that is when the reference rates of the Central Banks are unnaturally low.

We are not yet at the irreversible start of the speculation-financial crisis paradigm. Because in the absence of new interventions, the brief blaze will die out and the development potential will be reduced [5] [6] [7]. The problem becomes more pressing if the tension created by the improper relationship between the market and the low money cost, doesn't decrease. It's interesting to note that even in similar circumstances of market tension, the deflation continues to be soft; we can note just a brief accentuation of the cost of living, which anyway does not exceed $2 \%-2.5 \%$. At the same time, the great tension developed in those sectors subject to speculation doesn't seem capable to push the general growth of the economy, which remains medium-low (Figure 5).

We can imagine a sort of no-return point, beyond which the speculative mechanism can go on, then proceeding until the end of the financial crisis. In other words, it can be argued that even the speculative emphasis may fall within the context of the actions available to the correction mechanism, which is looking for a way to rectify the unstable system deviated path. As to say that if should fail all other ways to put back on track the unstable system, there would be no other option but to initiate the speculation-financial crisis paradigm. An extreme resource with effects so disruptive that, precisely because of these terrible effects, we must imagine that the economic system would always dispose of some alternative exits to avoid the implosion.

\subsection{Escape Ways Are Possible. It Might Be Better to Go Unarmed to the Appointment with Deflation}

Beware, however, to no-return threshold. At that point, the instruments of financial and monetary policy become just useless tools. The story is now driven
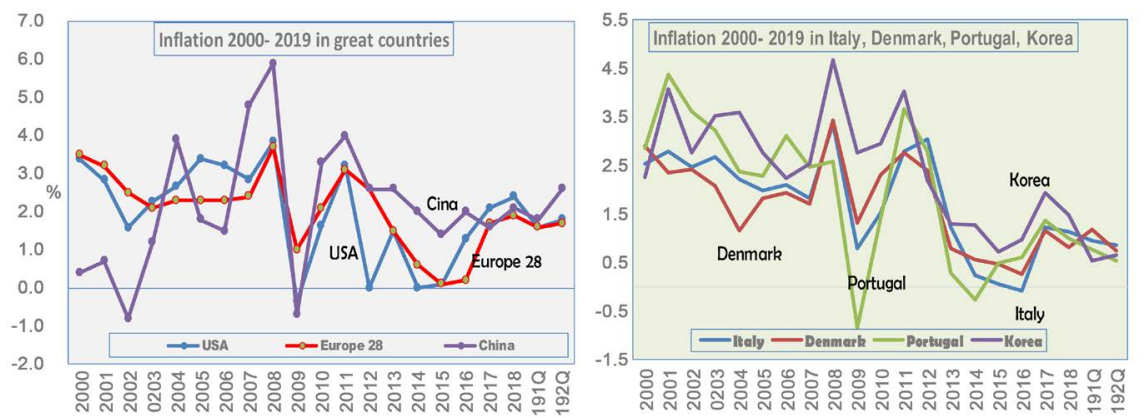

Figure 5. Inflation and GDP for quarter at the dawn of 2008-2013 financial crisis. Source: Elaborations on OECD data. 
by the "black hole" of the imminent financial crisis. So imminent yet totally unexpected. Institutions and companies are attracted by the speculative vortex that drives forward the quotations in the sector pushed by speculation. A sort of dreamlike indolence takes the operators, who seem somehow fascinated by the vortex created by virtual motion. So much virtual that it will be destroyed by the upcoming financial crisis.

But if we aren't at the point of no-return, each option obviously remains open and available. Because the problem is that the forming speculation vortex is fueled by proactive fiscal or monetary policies, which the market is continuously demanding to contain the economy's pressure towards recession. And then a limit must be imposed: there is no alternative. At least in order to prevent the whole degrading course of speculation-speculative crisis paradigm.

The scenario of the public and private indebtedness excess finds its possibility to grow, beyond the limits allowed by the real economy and by the capability to honor the commitments made, in the large liquidity available and in the parallel reduction of the money cost at historic lows. Not only: the trend can go forward because even the expiring debt creates new debt, in a context of low remuneration.

On the other hand, we shouldn't forget that the global economy is just emerging from a very serious financial crisis, which after ten years is still spreading its negative legacy. The current problems may also depend on the fis$\mathrm{cal}$ and monetary policy choices made at the time to mitigate the repercussions of the severe recession. We have no doubts about the results that allowed, during the acute phase of the crisis, to reduce the serious social damages. Nevertheless, let us not forget that the debt excess created in the 2000s with the speculation emphasis was simply transferred-at least in part-to the future through new debts.

Like to say that the problem was only apparently solved, because the natural correction mechanism cannot be tricked with operations, such as the cost of money below zero or the great availability of liquidity on the market. More correctly, we should talk then of postponement for the future of potential recession, which is therefore only temporarily mitigated.

At such a stage, which resembles so much to the current scenario, it's now essential to close the flow of monetary policy to avoid the progress of speculative phase. The key interest rates of the Central Banks shouldn't fall below the basic $2 \%$ threshold. If then this threshold has already been exceeded downwards, every option to further cut should be excluded, while we should consider the possibility of an upward adjustment, which would allow us to check the market behavior. Therefore, not the instinctive and reactive movement of the speculative market, but instead the most cautious and reasoned action that would consider the orientation of families and companies, in terms of trust in the near future. Now, a possible reaction of operators and families, just moderately pessimistic on the economic side, can be a signal that the direction taken is the right one.

We should understand that the exit from deflation is not a gift, because it in- 
volves a cost that cannot be postponed and then should be addressed as soon as possible. Unfortunately, the choice to favor the position of leadership continuously in the spasmodic search for a result, to which hang up their political consensus, might be a dramatic approach. Only in appearance and temporarily the usual options based on the most accommodating policy can meet the desired purpose. But the game of postponing sine die the accounts of an indebtedness excess, which cannot find relief, unfortunately can favor the speculative phase in germ, because the economy world remains in deflation.

Certainly, it seems easier or even more convenient, to listen to the "siren songs" coming from the market, also because the tension seems to fade. But we shouldn't fall into the trap prepared by the speculation-crisis paradigm. Certainly not for a sort of revenge toward a natural system of extremely hard and cruel correction, but because of that obstinate optimism leading us to believe we can carefully act in a deteriorated landscape, such as the instability world. That is, to believe we can bypass the conjuncture, which is a tool to correct instability and not a sort of economic snake that we can transform into a straight stick, like Abraham and Aaron in the Bible. ${ }^{8}$

The idea of an economy growing according to a straight and slightly rising movement is innate in our mind, but this could become real only if and when the economy would finally convert to the balance and sustainability. Nonetheless, it's useful also to point out that the current approach aiming to fight deflation with the cut in interest rates and the ultra-accommodative policy, doesn't seem to give results in terms of price weakness. On the other hand, also the expectation of an improvement in the economic cycle has no response, as we continue to persist with the monetary policy easing.

We must somehow admit that there is no alternative, when the economy is struggling with deflation. We shouldn't follow the instinct towards an easy but non-existing solution. It shouldn't be forgotten, however, that economic systems show a great elasticity and are always looking at very long time horizons. The economy instability comes from afar. Untreated, it passed from the long decade of great inflation to the equally long phase of deflation; a cure that has proven inadequate. The attempt to treat inflation, which is a sign and not the reason for the inappropriate price run, has launched us into an apparently inverse horizon of falling prices. We cannot continue to believe that the enemy is the image of evil and not the evil itself, that is the instability.

In the 1970s, the great global inflation was due to the attempt to live together with inflation. But the inflated prices follow a constant acceleration that with its progress depresses and suffocates every development. The same is true in the case of deflation, which is also depressing and suffocating the economic development. The remedies offered by monetary policy are all temporary and can fuel an abnormal development of public and private debt, which are the fire that can trigger the speculative crisis.

${ }^{8}$ Exodus 7: 8-13. 
Instead, we need to have confidence in the capability of communities to select the right program for the return to a natural balance in the economy. A trust that is well placed, indeed. Because we must admit that, if it's true that the global economic system is tending to stability, the keystone that is able to bring the economy back on the right path of a rectilinear growth must necessarily be inside the humanity itself, which is the recipient of the resources offered by the nature.

As saying that the way that can lead back to the correct path of natural balance in economy must be placed inside the DNA of humanity. A natural path of equilibrium that should be perceived by the majority of people as perceptions and sensations, which materialize in the form of implicit messages coming from the economic and natural environment. It can therefore be admitted that a serious, and above all sustainable, management of the economy should meet over time the consensus of the community's majority. Which should therefore be willing to accept the possibility of a temporary cycle reversal in the economy.

The singular willingness shown by the Italian electorate during the latest decades toward welfare-based interventions, despite the very high level of public spending and public deficit, should not be qualified as a deviation from the natural orientation. It's justified, in fact, by the great gap in the income and wealth distribution that required a revision in favor of the lower classes.

This is to say that the alterations produced by instability are translated into increasing social tensions. Therefore, the economy management must always take charge of these social alterations. Above all in order to make possible the social acceptance of a period with zero or even negative growth. So, having some mediation capability, it can be argued that a leadership could meet the consensus of the community, at least from its major part, even when it's proposed a program requiring sacrifices and further renunciations, at least in a first period. At the same time, envisaging a more stable world and a more responsible economy for the tomorrow world and above all for the new human generations.

This is a potentiality already available, it's true. As it's true that, in the absence of interventions or (even worse) for other monetary and fiscal policy incentives, become inevitable the slow formation of the speculation-financial crisis paradigm. At the same time, it must be presumed that an escape from the growing trouble of the deviated market, therefore, would always be possible.

Certainly, against this courageous and virtuous behavior, there are the never dead hopes that it would always be possible to make some actions against the recession with some success, even in the case of deflation and weakened economy. Moreover, the monetary policy adjustments over time are no longer virtuous. Indeed, they can be somewhat misleading, because the advantages are temporary and unequal. And, above all, they are unable to deal in any way with the danger of instability, which in fact may be ambiguously hidden to reappear soon, then accentuating the tendency of deflationary prices and weak economy.

Therefore, the problem is not about the escape from a recession that now follows the destiny of the global economy; but above all there shouldn't be any 
doubt about the capability of a community to perceive over time the correct direction in the economy management, in line with the balanced and sustainable growth.

\section{Conclusions}

The economy of sustainability can be represented as a methodology to make a connection between the real economy and the environment affecting the economic activity and the life of human beings. Sustainability cannot be defined only as the relationship between the use of the planet's resources and the natural potential for their recovery. Because, if we admit that this relationship balance is essential and has conditioned the long history of humanity over the millennia, then we have to ask ourselves: How and to what extent?

We can then accept that the sustainability economy is dominated by a physical law, just like all the laws governing the universe motion and, in the same way, assuring the life development on our planet. A law, is apparently simple at least in its formulation, but complex indeed in its practical execution. As already mentioned, it's the stability trend of economic systems which more or less postulate the human survival through the preservation over time of the resources made available for the whole life on the Earth, not just for the humankind. Now this rule, to be practiced, postulates that there are tools with the mere task of maintaining the balance between resources and their use.

As saying that there are tools to discipline the behavior of human beings in the economic environment: these tools are giving messages and news on the possible deviation from the balanced state of the economy, both locally or globally. The first tool that humanity has at its disposal, in order to stay on the almost balanced level of sustainability, is inside the human nature itself. The enormous never ending curiosity that has always led humanity to investigate and to study the nature around us, is the main instrument of the equipment that oversees the sustainability balance maintenance. We can presume that studying the mother Earth and her complexity and completeness, is therefore the best requisite to approach the innate predatory and selfish logic to the growing acknowledgment of the compatible use of natural resources, compatible use which is an advantage but also a reward, indeed.

Therefore, the science is increasingly the main driving force of the tendency to stability and the main mediator in the relationship between humankind and creation. This is obviously a relationship progressing over time and inevitably following the long times typical of the evolution of nature and its laws. Nevertheless, these long times are inexorable and will allow us to tighten the relationship between the human evolution and the nature supporting its development.

Of course, this relationship between science and nature is an expanding force, which has not yet the governance power and above all don't have predominance in the past. Therefore, it's clear that, during the long time of life on the planet, the tendency to stability has found the strength to promote and direct the development, over time, in a balanced form through the market's own behaviors. 
The first message coming from the market is double: the constant and long-term development that rewards the balanced growth conditions and, on the contrary, the uncertain and unstable growth weakness of those systems that have derailed from the sustainability path. It's singular that the economic science, which could be the board on which the human knowledge moves in sync, seems in practice to be delayed on the path of the correct relationship between economy and nature.

A problem that seems to lay in the inexhaustible presumption of the ruling classes in the economy management about the possession of the tools able to keep the economy constantly growing. A claim that overlooks the fact that the economy is able to follow a path of constant and growing development, provided that it doesn't deviate from the line of stability and natural sustainability. In other words, to obtain the reward of a constant and linear growth, we need to follow the relationship linking mankind and nature.

On the other hand, it seems the "Wizard of Oz" whoever would try to revive the exhausted economy, because so many errors were made in the common good management. But there's no magic at all. Because, although responsible for the economy poor performance, we are trying to revitalize the market, but without first trying to right the ship of the unstable economy, which therefore risks the bad waves of uncertainty and instability. Actually, the economy weakness is due to the fact that the economic system travels inside the instability sub-world and the conjuncture waves are the clearest symptom of the mistakes made in the economy management.

Insisting in the attempt to promote an improvement to obtain the expected results, however, could mean the postponement to the future of the natural corrective mechanism, which sooner or later will emerge despite fiscal or monetary policy maneuvers. The problem is that the tension toward stability is like a rubber band that can be pulled even for a long time but up to a certain limit. This indicates that the relationship between humankind and nature certainly tends to stability. However, this relation admits a reasonable degree of elasticity to compensate the movements created during the mutual relationship. This elastic relationship allows a partial dissymmetry between the nature evolution and the somehow rough path of the economic and social history of humanity.

Now this tolerance cannot be misinterpreted to the point of believing that we can force the relationship terms. More reasonable, instead, it's to argue that the possibility of a deviation is also contemplating the need, at some unspecified but not endless time, to simply go backwards in order to return on a sustainable path. As saying that the road bringing the economy back to balance is not free of charge. And the charge is paid in the case of inflation, with the accelerated nominal prices forcing over time to worsen the alteration of the economic cycle.

Following these reflections, we could believe that the time plays an essential role in the relationship between humanity and the environment around us. In the sense that we can imagine a continuous adjustment of the relationship, mediated by the science and perceived as a sort of catalyst solving the difficulties of 
the relationship. This means that over time we can expect a greater social balance, with the achievements resulting from a growing care towards the sustainable use of natural resources.

From the sustainability economy point of view, it must be said that the face to face struggle with the sinuous economic cycle may not make sense. In fact, the appearance of the economic cycle is due to the economic system fall into the instability sub-world. In this different context, the transformation of the stability constant cycle into the instability sinuous cycle is due to the recession arrival in the economic horizon. The recession would be nothing but the correction tool adopted by the economic system to try to correct the economy management errors, responsible for the instability.

Therefore, it's just a cure adopted by the natural correction mechanism to restore balance. Then, blocking or braking and altering the cycle direction wouldn't seem an appropriate choice. It must be said that fiscal and monetary policy maneuvers could weaken the cycle and delay the cycle adverse wave, so giving the feeling that we are able to control the economic conjuncture evolution. It's probably a short-sighted vision, because we can only transfer to an unspecified future the inevitable choice to re-establish the links with the sustainable economy path.

According to this point of view, even more singular would seem the choice to fight against the nominal price movements. Both inflation and deflation are like ectoplasms awakened because of the economic instability and are neutral about the economy's motion. It is rather the economy's cycle that badly changes and accelerates due to the instability permanence, which is the cause altering the economy. It is only apparently that the course of nominal prices would affect the economy movement, while it is the cycle deterioration that changes the market trends and expectations.

In practice, both inflation and deflation are just messages that the system offers to the community to make us aware about the distance degree that separates us from the economic balance. It is consequently a formal deviation, without effects on the economic context, except what comes from the mere alteration of nominal values. Just a malaise signal and not a malaise itself. A disease fever and not a disease.

Now it's clear that being unaware messengers of the unstable condition, families and companies would change their expectations towards the market and would act accordingly even anticipating some economy's complaints. Thus, it's achieved a sort of convergence of the operators' intentions that anticipates or at least follows the diverging tension of the conjuncture. This is how is produced the "optical" sensation that the movement in nominal prices is the cause of the economic malaise. But this is just a sort of mirage which doesn't alter the basic issue. Both inflation and deflation are messengers without any power on the basic economic motion and they give signals to the community in order to understand that we are walking inside the instability sub-world and not inside the stability world. 
Because of their nature as instability ectoplasms, we can also say that the fight against the actions of nominal prices may not make sense. That is, it might make sense only if we realize that the true objective is the economy state and the conjuncture trends and, above all, that we are inside the instability sub-world. And in this instability sub-world the real enemy is not the nominal prices or the conjuncture destiny, but the deviation from the sustainability path.

\section{Conflicts of Interest}

The author declares no conflicts of interest regarding the publication of this paper.

\section{References}

[1] Bernanke, B.S. (2000) Essays on the Great Depression. Princeton University Press, Princeton, New Jersey.

[2] Money and Market-Volcker, Bernanke, Greenspan, Yellen Beg for Fed Independence.

https://moneyandmarkets.com/paul-volcker-ben-bernanke-alan-greenspan-janet-ye llen-federal-reserve/

[3] Cossiga, G.A. (2018) Signals from the World of Economics. The Price Constant and the Democratic Issue. International Journal of Social and Administrative Sciences, 3, 1-21.

[4] Cargill, T.F., Hutchison, M. and Tadayoshi, I. (1997) The Political Economy in Japanese Monetary Policy. First Edition, The MIT Press, Cambridge, Massachusetts. https://doi.org/10.7551/mitpress/5440.001.0001

[5] Cossiga, G.A. (2018) A New Financial Crisis Could Start Again from the USA. Advances in Social Sciences Research Journal, 5. https://doi.org/10.14738/assrj.511.5521

[6] Cossiga, G.A. (2017) Stability and Instability of an Economic System: Considerations. Review of European Studies, 9, 8-20. https://doi.org/10.5539/res.v9n3p8

[7] Cossiga, G.A. (2018) The Search for Inflation on a Constant Basis at 2\%. Social Sciences, 7, 165-181. 